\title{
HERMENÉUTICA EXISTENCIAL EN SER Y TIEMPO DE MARTÍN HEIDEGGER*
}

\author{
Miguel Ángel Barragán D.** \\ Juan Cepeda $H^{\star * *}$
}

\section{Resumen}

El paradigma hermenéutico ha abierto un horizonte amplio a la hora de interpretar y comprender textos, pero ha cerrado las posibilidades existenciales que ya en Ser y tiempo abriera Heidegger. Lo que se intenta aquí es señalar esos presupuestos ontológico-existenciales que indicara acertadamente el filósofo alemán en su momento. El avance que se presenta hace parte del proyecto de investigación "Ontología en América Latina" que lidera el grupo de investigación Tlamatinime. La primera parte tiene como objetivo fijar cuatro lineamientos que estructuran la propuesta de una hermenéutica existencial: 1. La disposición afectiva como afectación y responsabilidad. 2. El comprender afectivo. 3. El comprender como interpretación. 4. El sentido. La segunda parte, consiste en presentar lo que se vislumbra por hermenéutica existencial y cuál sería su propósito.

* El presente artículo es un producto de investigación del proyecto "Ontología en América Latina", que lidera el grupo de investigación Tlamatinime, interfacultades e interinstitucional (USTA Uniminuto). Citar como: Barragán, M y Cepeda, J. (2018). Hermenéutica existencial en ser y tiempo de Martín Heidegger. Cuadernos de Filosofía Latinoamericana, 39(118), 115-141. DOI: https://doi. org/10.15332/10.15332/s0120-8462.2018.0118.07

* Licenciado en Filosofía y Lengua Castellana de la Universidad Santo Tomás. Magíster en Filosofía de la Universidad de los Andes. Correo electrónico: mianbadi@gmail.com

*** Licenciado en Filosofía y Letras. Magister en Filosofía Latinoamericana. Doctor en Filosofía de la Universidad Santo Tomás. Correo electrónico: juancepeda@usantotomas.edu.co 
Palabras clave: contología, ser, existencia, afectación, sentido, hermenéutica existencial.

\section{Abstract}

The hermeneutical paradigm has opened a broad horizon when it comes to interpreting and understanding texts, but it has closed the existential possibilities that Heidegger already opened in Being and Time. What is endeavored here is to point out those ontological-existential presuppositions that the German philosopher rightly indicated at the time. The progress presented is part of the research project "Ontology in Latin America" led by the Tlamatinime research group. The first part aims to set four guidelines that structure the proposal of an existential hermeneutics: 1 . The affective disposition as affectivity and responsibility. 2. Affective understanding. 3. Understanding as interpretation. 4. The meaning. The second part, to present what is glimpsed by existential hermeneutics and what would be its purpose.

Keywords: Ontology, being, existence, affectivity, meaning, existential hermeneutics.

\section{Resumo}

O paradigma hermenêutico tem aberto um horizonte amplo para interpretar e compreender textos, mas tem fechado as possibilidades existenciais que já em Ser e Tempo iniciasse Heidegger. O que se tenta aqui é assinalar esses pressupostos ontológico-existenciais que indicasse acertadamente o filosofo alemão em seu momento. $\mathrm{O}$ avanço que se apresenta faz parte do projeto de pesquisa "Ontologia na América Latina" que lidera o grupo de pesquisa Tlamatinime. A primeira parte tem como objetivo estabelecer quatro diretrizes que estruturam a proposta de uma hermenêutica existencial: 1. A disposição afetiva como afetação e responsabilidade. 2. O compreender afetivo. 3 . O compreender como interpretação. 4. O sentido. A segunda parte consiste

* Este artigo é um produto de pesquisa do projeto "Ontologia na América Latina", que lidera o grupo de pesquisa Tlamatinime, interfaculdades e interinstitucional (USTA - Uniminuto). 
em apresentar o que se vislumbra por hermenêutica existencial e qual seria seu propósito.

Palavras-chave: ontologia, ser, existência, afetação, sentido, hermenêutica existencial.

\section{Estructura formal de los lineamientos estructurales para la propuesta de una hermenéutica existencial}

Desarrollar una estructura formal significa utilizar los materiales más adecuados para construir algo. En este caso, los materiales para esta propuesta existencial son los constitutivos cooriginarios del Dasein: la disposición afectiva y el comprender ${ }^{1}$ que se encuentran condensados significativamente en los parágrafos 28 a 32 de Ser y tiempo. La distribución de este numeral se compone de la siguiente manera: primero se ahondará en lo que significa constitutivo cooriginario, y el término de Befindlichkeit traducido como disposición afectiva.

Constitutivos originarios: el término constitutivo proviene del latín constitutivus, que significa la parte fundamental de algo y que se distingue de los demás. En cuanto proviene del verbo constituir es sinónimo de construir, lo que significa formar,

1 ¿Por qué no se tiene en cuenta el lenguaje? Porque parece ser que la apreciación de Heidegger al respecto no es la más precisa, si bien en el parágrafo 34 se introduce al discurso o habla como constitutivo, posteriormente, y a lo largo de Ser y tiempo se muestra vacilante ya que unas veces lo afirma como constitutivo (véase las páginas $161,202,270,335$ ) pero en otras ocasiones no ocurre lo mismo (véase por ejemplo las páginas 133, 148, 183, 189, 160, 211, 261, 270, 289). Esta imprecisión que queda, sería mejor plantearla para un nuevo trabajo investigativo. En todo caso, también, algunos estudiosos sobre el pensamiento de Heidegger se inclinan por una u otra propuesta, aqui ya se ha mentado la posición de este trabajo al igual que otros investigadores heideggereanos; quizás algunos peritos justifiquen que el direccionamiento se hace teniendo en cuenta la segunda fase del pensamiento de Heidegger también conocido como el giro (Die Khere) donde está focalizado hacia el lenguaje. Ante las justificaciones de que el discurso sea un constitutivo se podria afirmar entonces que también el término de caída (Verfallen) lo es; el mismo Heidegger lo manifiesta por ejemplo en dos ocasiones consecutivas en el $\$ 54$ y $\$ 55$ al decir que al Dasein lo constituye la disposición afectiva, el comprender, el discurso y el lenguaje (curiosamente en el mismo parágrafo se afirma que la disposición afectiva le pertenece cooriginariamente el comprender; se evidencia pues una vacilación del mismo Heidegger) o como lo afirmará en la parte d del §68; pero tampoco esa es la cuestión aquí. La cuestión radica en que tanto el discurso como la caída son importantes conductores existenciales de lo cotidiano y donde por supuesto descansan en los constitutivos cooriginarios del Dasein. Como se observa, el hecho de que no se tome como constitutivo cooriginario no significa que se descarte entonces en su totalidad. 
componer, fundar, integrar y configurar algo. En este caso, el término constitutivo justifica que algo es vital en el ser del Dasein. Con todo, si hay algo que confirme lo anterior, que ofrezca suelo, consistencia, mayor precisión y fundamento a esto, es la

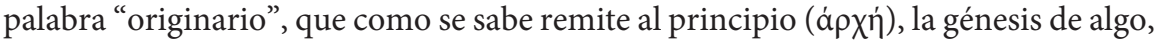
al inicio y nacimiento, al primer comienzo. De esta manera, lo que se pretende aquí al reflexionar sobre "constitutivo cooriginario"2 es observar qué partes son fundamentales en el Dasein y cuáles son las más primarias. La función de los constitutivos es "Diese muss darauf zielen, ans licht zu bringen, worin die Grundstrukturen des Daseins in ihrer einheit und Ganzheit Gründen"3 (Heidegger, 1975, p. 322), de donde para Heidegger es de vital importancia estudiar exhaustivamente al Dasein lo mejor posible, por eso cuando la sentencia heideggereana habla de unidad y totalidad se está refiriendo expresamente a lo que hace ser al Dasein lo que es, en este caso, la disposición afectiva y el comprender como sus constitutivos cooriginarios.

Otra cuestión que es evidente en la obra de Heidegger es la relación con los términos alemanes Dasein y Befindlichkeit, que presentan cierta dificultad a la hora de su traducción; aquí se considera pertinente explicar cómo el término Befindlichkeit que se he traducido como disposición ${ }^{4}$ afectiva ofrece algunas connotaciones implícitas para la propuesta existencial. La disposición afectiva siempre hace alusión al modo como está y como le va, según lo expuesto por Heidegger (1975, p. 134); además se debe tener en cuenta que el término también significa humor. Al reflexionar sobre

2 Dicha expresión en el texto alemán aparece como: Gleichursprünglichen. Gleich significa igual, igual que; Ursprünglich significa originario, inicial, originalmente, el principio.

3 Poner de relieve la existencia y poner de manifiesto en qué se fundan las estructuras fundamentales del Dasein en su unidad y totalidad.

4 Además, las acepciones de la palabra disposición pueden indicar: preparación, acogida, orden, adecuación, motivación, expectativa, anticipación, previsión de las condiciones necesarias para ejercer una tarea cualquiera, por ejemplo: el auditorio (lugar) está adecuado para presentar y escuchar una conferencia, adicionalmente se prevé que la mayoría del público no sabe francés, por lo tanto, se necesita de un traductor y los equipos necesarios para escuchar la traducción (audifonos y dispositivo especial); el estudiante ha preparado su examen y se encuentra en disposición de presentarlo; la forma como dispongo los ingredientes para hacer un plato favorito. Utilizamos frases para decir: Adriana está enferma y no se encuentra en disposición para ir a trabajar; se ha adecuado el apartamento para la fiesta; me arreglo para la fiesta de esta noche; me emociono con la cita que tengo esta noche y estoy dispuesto a asumir sus consecuencias; tengo la disposición de arreglar los conflictos con mis amigos; el sacerdote puede hacer un rito de entrada para disponer a sus feligreses para la eucaristia; el político incita al pueblo a votar por él como la mejor opción; el maestro trae una poema para disponer a sus estudiantes al iniciar la clase; el equipo de fútbol tiene varios planes tácticos en caso de no darse el resultado o las condiciones para ganar el partido. Con estos ejemplos, se puede apreciar que la palabra disposición guarda mayor significación que encontrarse en. 
la palabra humor pueden entenderse por lo menos dos sentidos. Primero, humor como referencia al carácter de estado de ánimo, ya sea alegre, jocoso y chistoso o hasta serio y amargado, que sería mal humor, verstimmung (Heidegger, 1975, p. 134). Segundo, puede percibirse el humor a nivel fisiológico y biológico como algo íntimo de la persona, como aquellas sustancias que son producidas a nivel hormonal y que son expulsadas por el cuerpo para determinar, por ejemplo, su aroma u olor. Alguien puede decir: aquella es una persona de buen humor, señalando el carácter de un estado de ánimo, en este caso de alegría; otra persona puede referirse a otra con la expresión: fulano de tal tiene un humor fuerte refiriéndose a su aroma u olor. Las dos connotaciones también se relacionan en un estado de ánimo que se refleja corporalmente, "Dass zu den Affekten und Leidenschafen und Gefühlen auch jenes gehört, dessen sich die Physiologie bemächtigt -bestimmte Leibzustände, Veränderungen der inneren Sekretion, Muskelspannungen, Nervenvorgänge"5 (Heidegger, 1961, p. 55). Pero estas surgen mucho después de un estado de ser que se ha abierto estando en el mundo, en otras palabras, tales manifestaciones fisicoquímicas son el producto muy posterior de una determinada forma de ser que ha aflorado en el Dasein ${ }^{6}$.

No obstante, cabe la advertencia de que aunque la reflexión sobre el humor ha conducido a distinguir características en el sentido biológico, químico y fisiológico, no se debe confundir y olvidar que las disposiciones afectivas son modos ontológicamente (entiéndase lo ontológico como lo más primigenio, que yace en el hombre para

5 Es innegable que, a los afectos, las pasiones y los sentimientos les pertenece también todo aquello de lo que se ha adueñado la fisiologia: determinados estados corporales, alteraciones de las secreciones internas, tensiones musculares, procesos nerviosos.

6 Ambos significados pueden ser y no ser válidos al mismo tiempo porque se estaría cayendo en un peligro, sobre todo con el significado último de la palabra humor; es válido en cuanto que representa el camino a la reflexión y de cierta manera se manifiestan rasgos óntico-corporales; no es válido sobre todo en cuanto que no determina suficientemente un camino ontológico según la propuesta heideggereana. De modo que consideramos esto una razón más para utilizar el término de disposición afectiva, pues de acuerdo con sus disposiciones, emanará diferentes olores y ante todo modos de ser. Es preciso advertir que lo que interesa evidenciar de la palabra humor es el ejemplo y su servicio que se ofrece como herramienta hermenéutica clave para comprenderla nada más. No interesa realizar un curso de biología, química y física, como sí le puede interesar quizás a la medicina, la robótica, a la inteligencia artificial, a la neurología o a otras ramas de la ciencia para observar qué pasa con nuestro cuerpo, cómo y en dónde se producen sustancias tales como la dopamina, la adrenalina, acetilcolina y cómo se produce el pensamiento, etc. Quizás sea una justificación válida si se tiene en cuenta que química y biológicamente, por ejemplo, cuando dos personas se encuentran expulsan diferentes sustancias de su cuerpo y estas serán aceptadas o rechazadas tanto de una y otra persona, es más, su apariencia física se puede alterar dependiendo del quién se hace presente. Sin embargo, tales manifestaciones fisicoquimicas son el producto y muy posterior de una determinada forma de ser que ha aflorado en el Dasein. 
determinar su forma de ser) existenciales y fundamentales del Dasein y en donde dichas disposiciones ya han aflorado en este muchísimo antes de que se manifiesten corporalmente.

\subsection{La disposición afectiva como afectación y responsabilidad}

Este primer lineamiento girará en torno a la disposición afectiva que tiene el carácter de afectación y que incide en la vida del ser humano. Luego, se develará cómo el carácter de afectación puede derivarse en un asunto de responsabilidad. Así pues, la reflexión de este lineamiento se centra y desarrolla desde la siguiente afirmación:

Die Befindlichkeit erschließt nicht nur das Dasein in seiner Geworfenheit (...) ie ist selbst die existenziale Seinsart, in der es sich ständig an die »Welt« ausliefert, sich von ihr angehen läßt derart, daß es ihm selbst in gewisser Weise ausweicht. Die existenziale Verfassung dieses Ausweichens wird am Phänomen ${ }^{7}$. (Heidegger, 1967, p. 139)

El primer elemento para tener en cuenta es el carácter de arrojado, que juega un papel protagónico en las estructuras originarias del Dasein. La condición de arrojado significa el modo como vive habitualmente (Heidegger, 1967, p. 139). Que el Dasein esté arrojado en el mundo indica que desde el momento de su existencia está en un mundo al que debe enfrentarse, al que le toca vivir, en el que se encuentra ante unas circunstancias que él nunca pidió ni eligió y que son determinantes en la manera de afrontar su vida, y su modo de ser; desde que el Dasein está en el mundo él sabe qué es pero su de-dónde y adónde de su ser quedan en la oscuridad, al mismo tiempo señala que "Seiendes vom Charakter des Daseins ist sein Da in der Weise, daß es sich, ob ausdrücklich oder nicht, in seiner Geworfenheit befindet"8 (Heidegger, 1967, p. 139). Ya que siempre está entregado al mundo con ciertas posibilidades de ser y por supuesto se encuentra con determinada disposición afectiva.

7 La disposición afectiva no solo abre al Dasein en su condición de arrojado (...), sino que ella misma es el modo existencial de ser en el que el Dasein se entrega constantemente al 'mundo' y se deja afectar de tal modo por él, que en cierta forma se esquiva a sí mismo.

8 El ente que tiene el carácter de Dasein es su Ahí de un modo tal que, explícitamente o no, se encuentra a sí mismo en su condición de arrojado. 
La condición de arrojado indica que la afectividad es tan sustancial en el ser del humano, está tan arraigada y al mismo tiempo tan escondida en él, que solo en esa forma de ser se sabe que existe. El Dasein en gran medida existe por su disposición afectiva; en ella se determina su mundo, sus conocimientos, todas sus experiencias y expectativas de la vida. La disposición afectiva determina la apertura de cómo el ser humano se ofrece al mundo y este se ofrece a él. En la proposición de este lineamiento se sostiene que ella (la disposición afectiva) es el modo existencial como se entrega el ser humano al mundo y se deja afectar por él. Para Heidegger siempre estamos asistidos por los estados de ánimo, que pueden cambiar de un momento a otro, ser fugaces, pasajeros y solo prueban que el Dasein es importante para dicha disposición.

El segundo elemento de este lineamiento es el se deja afectar. Generalmente la palabra afectar tiene muchas veces una connotación negativa, en este sentido tiende a relacionarse con la palabra perjudicar, hacer daño a algo o a alguien, ya sea físico, moral, psicológico, político o económico. Sin embargo, la palabra afectar también puede indicar un efecto positivo. La afectación tiene su influencia en la vida del ser humano. Todo lo que existe en el mundo nos afecta. Afectar significa cambiar y permanecer, ya sea de modo negativo o positivo. Afectar en el Dasein abarca el binomio del estímulo-respuesta, afectado-afectante, en otras palabras, es acción ${ }^{9}$.

El ser humano es afección o afectación, su existencia depende de eso; en sentido aristotélico $^{10}$ la afección se refiere a los infortunios y penas, pero también a una alteración de ciertas cualidades, como lo dulce y amargo, pesadez y ligereza entre

9 Afectar: estimulo respuesta, afectada-afectante. La manera como nos ocupamos en la vida, en la que nos encontramos siendo en el mundo diariamente (que sería la condición de arrojado) tiene su re-acción puesto que al Dasein le corresponde tener que ser y sabe que es por su temple anímico. En otras palabras, todo acto que se haga (estimulo/afectada) tiene efectos (respuesta/afectante), todo acto que se realice por más insignificante que sea afecta nuestro modo de ser y afecta la manera de ver el entorno en el que andamos, es decir, no solo afecta a quien hace un acto sino todo lo que lo rodea.

10 Se tiene en cuenta la definición de aristotélica de "afección" porque en las notas de pie de página de los parágrafos 29 y 30 de Ser y tiempo se remite a la Metafísica y la Retórica del estagirita. Asi, se hace evidente la influencia de Aristóteles en Heidegger. Sin embargo, los estudios de la disposición afectiva como afección ya se pueden entrever mucho antes de Ser y tiempo, en 1924 ofrece un seminario titulado Grundbegriffe der aristotelischen philosophie, Los problemas fundamentales de la filosofía aristotélica (traducción del autor, hasta el momento no existen traducción al español de esta obra), gran parte de su curso tiene como referentes a la Metafísica y la Retórica del estagirita, entre los términos griegos que más destaca está el de $\pi \dot{\alpha} \theta \eta$ como disposición afectiva, su reflexión se puede confrontar en todo el parágrafo18, donde habla de lo que significa y de la manera como hace parte de la estructura general de la existencia humana o del Dasein. 
otras, dando así un sentido más bien negativo, pero como se sabe, Heidegger concede importancia al pensamiento del estagirita y retoma el término $\pi \dot{\alpha} \theta \eta$ del segundo libro de la Retórica (Heidegger, 1967, p. 139) para ahondar su reflexión sobre la disposición afectiva como afección, y resaltar al mismo tiempo la poca importancia o tergiversación que se le ha dado en el trascurso de la historia. El término griego $\pi \dot{\alpha} \theta \eta$

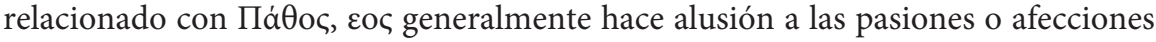
que el ser humano puede tener, ya sea como un dolor físico, que si es prolongado se le puede llamar enfermedad, o algo menos palpable como la afección del alma, aunque también ha de verse en el modo de un sentimiento, de una emoción viva, de una pasión, de un movimiento pasional. Llaman la atención las dos connotaciones que puede significar el Пá 0 oc: la del padecer y lo pasional, que por un lado tienen mucha afinidad con lo que pretende vislumbrar en cuanto a sentimientos se refiere. Ahora bien, no se trata de ver los $\pi \dot{\alpha} \theta \eta$ como enfermedad física o un estado mental, sino que es lo que caracteriza al ser humano estando en el mundo (Heidegger, 2002, p. 192).

Se padece con nuestros estados afectivos, no como un padecimiento de manera negativa, como enfermedad, sino algo que va adherido al ser del Dasein, es un padecer que se experimenta afectivamente como una carga (Heidegger, 1967, p. 134) que puede ser muy pesada o liviana, algunas veces se puede sufrir o gozar por hacer una actividad y de acuerdo con el estado anímico se revelará como carga y otras veces como pasión (emocionante). Lo cierto es que la afinidad más importante está referenciada para las disposiciones afectivas, ya que el carácter de lo pasional manifiesta la fuerza más profunda y dinámica que reside en los temples anímicos: se agitan las fibras más hondas de la existencia y las agita negativa, indeterminada o positivamente, en otras palabras "Die stimmungen das ist solches, was in us Lust oder Unlust erweckt, worauf wir dementsprechend zu reagieren haben"11 (Heidegger, 1983, p. 238). El sentido heideggereano del término pathé hace alusión al acto de padecer las cargas emocionales que tiene el ser humano en cuanto afecta su existencia.

El modo de percibir el mundo es porque el Dasein está afectado por sus temples anímicos y por los de otros Dasein y todo lo ente que se hace o no presente de una u otra forma. El modo como abre y proyecta su ser es en la afección, no solo en

Para ver en detalle la influencia de Aristóteles respecto a la ontología de Heidegger puede consultarse el texto de Franco Volpi, titulado Aristóteles y Heidegger.

11 El temple de ánimo: eso es algo que despierta en nosotros placer o disgusto, a lo que tenemos que reaccionar de modo correspondiente. 
cuanto a las cosas sino a las personas. Se puede deducir que la afección es re-acción (no importa si es pasiva o activa ${ }^{12}$, simplemente es re-acción) ya sea ante las cosas o ante la coexistencia y el permanentemente estar ocupado, ella imprime el carácter de ser Dasein y donde "todo afecta y es afectado porque somos acción (...) el modo de afectarse del ser humano no es idéntico al modo de afectarse de todo ente" (Cepeda, 2007, p. 23). Es más, ni siquiera el modo de afectación es igual entre humanos, quizás exista una relación de experiencia similar, pero jamás la misma experiencia de afectación, aunque se pueda vivir en la misma circunstancia siempre nos afecta, pero no en el mismo grado de intensidad y de ese modo es una forma de estar en el mundo de cada ser humano, cada uno según sus posibilidades de comprensión, desde su sentipensar más propio (Cepeda, 2017).

La experiencia vivida humanamente es tan íntima y fundamental que de este modo se percata del alcance de afección que puede tener un ente, un suceso natural, una persona, e incluso se reconoce la dimensión que tiene un temple anímico ante algo que lo altera de sobremanera. En efecto, ciertos tipos de afección que el Dasein logra vislumbrar y quizá le puedan sobrevenir son esquivados por él mismo; precisamente por las propias vivencias que ha tenido o por las repercusiones que poco le favorecen. Hay ciertos lugares, estados de cosas y situaciones que el Dasein prefiere evitar, que esquiva justamente por lo incómodas que le resultan. Las esquiva porque se siente afectado, tal vez sin dimensionar la propia medida de ser afectante. También en esto suele consistir el miedo: es un modo de afectación ante la apertura de algunos rasgos que se manifiestan estando en-el-mundo; si una persona no pudiera sentir miedo no se le abriría ese rasgo, solo porque es capaz de tener miedo se le abre el rasgo de lo amenazante, de lo peligroso, de tal manera que el miedo tiene una función develadora, deja que la situación se manifieste y esto, por supuesto, tiene que ver con el carácter del estado abierto del factum, por eso es que puede ser experimentado y percibirse como afección. Pero esto no pasa solo con el miedo sino con cualquier disposición afectiva.

12 Las formas como el ser humano se re-acciona ante una circunstancia son múltiples. Entiéndase que la re-acción pasiva se identifica con hacer las cosas de manera tranquila, sin afanes, pero también de mostrarse con una reacción ociosa. La re-acción activa se identifica al cómo el ser humano actúa a una circunstancia de forma rápida, ágil, pero a esta forma de actuar también le cabe que se hagan las cosas de manera desesperada, angustiada hasta el punto de perder la cabeza, pues todo lo hace afanadamente. Dependiendo el modo como reacciona el ser humano se determinará si es activa o pasiva. 
Se puede deducir que la afectación es una re-acción, se re-acciona porque se siente y se experimenta algo que afecta, algo que se hace presente, incluso en la más absoluta indiferencia ante la vida; con razón Heidegger dice que el Dasein tiene que ser (estar) existiendo con sus temples de ánimo y estos afectan el modo como uno está. Lo que indica entonces que simultáneamente durante toda la vida se está re-accionando. Ahora bien, si la afección es una re-acción es porque todo afecta a todo; sea en el contexto que sea, la reacción en cualquier estado afectivo no conoce su propio alcance $\mathrm{y}$, sin embargo, su virtud es la de ser responsable porque responde por las cosas que pasen. La afección en cuanto re-acción abarca el binomio afectado-afectante, "cobra un sentido, sentido de responsabilidad" (Cepeda, 2007, p. 24). Por eso al hablar sobre este sentido de responsabilidad ${ }^{13}$ no se trata de abordar una cuestión ética sino de hermenéutica desde una perspectiva existencial que ha de considerarse como el modo de apertura en que se encuentra el Dasein y el modo como es contestatario ante las circunstancias de su propia existencia, la de otros Dasein y la de otros entes. Así, el sentido de responsabilidad en cuanto producto de la afección cumple lógicamente una función develadora, porque deja que el ritmo de la situación fáctica se manifieste y el Dasein responde asumiendo su existencia con lo que le toca o precisamente para que tenga su carácter esquivador.

Responsabilidad significa, entonces, responder y la forma como responde el Dasein es desde su condición de arrojado: él responde por su ser sin importar cómo, así sea en la manera de esquivar, de huir o cerrarse ante las circunstancias que se le dan en su estar-en-el-mundo. En este sentido, la responsabilidad es ontológica. La responsabilidad se da en el modo como afectivamente se encuentre el ser humano, incluso cuando su actitud fuera la de ser indiferente, esa es su forma de responder ante lo que vive y es al mismo tiempo como se abre al mundo, sus circunstancias.

Así se confirma que el ser humano durante toda su vida está siendo asistido por distintas disposiciones afectivas, ellas inciden en la forma de comprender lo que pasa a su alrededor, con los otros y consigo mismo; por eso Heidegger afirmaba que el estado anímico refleja el modo como uno está y como le va (Heidegger, 1983, p.

13 Aunque Heidegger no menciona para nada de un sentido de responsabilidad, se pude deducir que de ella se desprende esta caracteristica justamente por el modo como la afectación reside en toda disposición afectiva. Esta deducción se funde a partir de lo que puede ser una propuesta de hermenéutica existencial en cuanto su dimensión afectiva. 
134). La forma como vive el ser humano en el mundo se encuentra afectada por su estado anímico y, en consecuencia, el Dasein por su carácter de afectación (desde la disposición afectiva) es a su vez partícipe y responsable de lo que pueda pasar con los otros y consigo mismo. El resultado de la disposición afectiva es que siempre incide en la forma de comprender las cosas con las que se encuentra el Dasein en su diario vivir. Se puede considerar, entonces, que el carácter de afectación es la realización de la disposición afectiva y se constituye en un elemento vital del ser humano.

Así, la disposición afectiva como afectación y responsabilidad se convierten en el primer lineamiento de lo denominado como hermenéutica existencial. Lo dicho en esta propuesta existencial se podría expresar así: que los sentimientos pesan de manera tajante en la vida del ser humano; por su disposición afectiva es un ser que afecta y es afectado en la manera de pensar y actuar, que conlleva explícitamente o no a asumir una responsabilidad con todo lo otro, con los entes, los que están a la mano, los entes de su misma especie (Dasein) y consigo mismo.

\subsection{El comprender afectivo}

El segundo lineamiento para esta propuesta existencial se despliega especialmente en el parágrafo 31 de Ser y tiempo, cuando Heidegger afirma que el comprender es afectivo, de ahí que todo el despliegue de esta reflexión se concentre en la dimensión afectiva del ser humano y de aquello que pueda significar el comprender para una hermenéutica existencial.

Este lineamiento gravita en la siguiente proposición: "Verstehen ist immer gestimmtes (...) Grundmodus des Seins des Daseins" 14 (Heidegger, 1967, p. 143). Esta sentencia es capital para la construcción de lo denominado hermenéutica existencial, porque rompe con la postura que habitualmente se tiene del comprender: se tiene la concepción de que es un ejercicio de la razón, de tener la capacidad de entender, captar, juzgar e interpretar algo, ya sea una situación, un discurso o un texto como tal, y del cual se preocupa de esto último la hermenéutica tradicional. Sin embargo, el autor de Ser y tiempo acotará que ese ejercicio de la razón es tan solo un modo del comprender, más aún apuntará que el ejercicio de leer textos es simplemente un modo del interpretar. Con la proposición que hace Heidegger está diciendo que hay un comprender que

14 El comprender es siempre un comprender afectivamente templado (...) un modo fundamental del Dasein. 
es más primario y está caracterizado como afectivo y se da en la vida fáctica; el comprender "deja de ser un concepto metodológico de una operación que a contrapelo de la vida tiende hacia la idealidad del sentido y pasa a ser rasgo ontológico de la vida humana" (Gutiérrez, 2002, p. 179), de la esencia del ser del ser humano.

Que el comprender en el Dasein esté afectivamente templado, lleva a deducir que es un estado de ánimo -en cuanto que existe en el mundo-, y que no es meramente el uso puro de la razón, sino que, jen él se juega la afectividad del ser humano en cuanto que está abierto al mundo! Por eso cuando se le dice a alguien: ¡te comprendo!, significa que tomo la situación del otro, que la asumo, la cargo, la vivo, la experimento. Decir: "te comprendo" es afectarse de la situación del otro, es colocarse en los zapatos del otro, no simplemente como un momento para entenderlo cuando nos comparte su experiencia, sino que el otro deja de ser otro, porque ya lo comprendo y en la comprensión, me lo he apropiado (Cepeda, s.f.). La comprensión afectiva surge desde el estar en el mundo, es decir desde lo que el ser humano realiza en su vida ${ }^{15}$.

Con aquella expresión de que el "comprender es afectivamente templado" Heidegger relaciona y fusiona los dos constitutivos originarios del ser del ser humano; por una parte, está afirmando que lo esencial de la existencia es comprender, pero al mismo tiempo es afectiva (Heidegger, 2000a, p. 332). Por otra parte, con esta propuesta del comprender se está rompiendo con la postura habitual al pensar o hablar del comprender, pues no se reduce simplemente al carácter epistemológico que tiene el Dasein, no es simplemente un conocer, un dato más en la memoria, sino que el comprender es un estado de ánimo en cuanto que se vive en el mundo y se abre a este, es un rasgo esencial de la existencia humana. Así, este comprender afectivo, según Heidegger, es el más primario (1967, p. 143), y es el modo fundamental del existir, es decir que el Dasein se ocupa de su ser, ya sea de la manera más propia, o impropia; en el comprender se funda la cotidianidad y por supuesto su modo de ser al estar y ser-con otros, de forma que la esencia del Dasein es la existencia en cuanto comprende afectivamente en su diario vivir.

El comprender en el diario vivir consiste en aquello que el Dasein puede-ser, "Im Verstehen liegt existenzial die Seinsart des Daseins als Sein-können"16 (Heidegger,

15 Esto complementa lo dicho sobre el sentido de responsabilidad que tengo por el otro en cuanto al modo de afectación, no en el mismo grado de intensidad, pero sí como un punto de apoyo a eso otro.

16 En el comprender se da existencialmente ese modo de ser del Dasein que es el poder-ser. 
1967, p. 143). El Dasein, por estar en el mundo, por su aperturidad y su comprender, es un mundo de múltiples posibilidades; al Dasein le es posible ser... ¿ser qué? "No importa qué, no importa lo que pueda ser, el ser humano puede ser. Y por ello Heidegger lo califica como un poder-ser" (Cepeda, 2003) y a pesar de tener múltiples posibilidades solo puede tomar una, solo puede ser-se (en) una posibilidad. Lo más propio del comprender es poder-ser, por eso el Dasein estando en el mundo, en su cotidianidad, en su ocupación es que él es y puede ser, el comprender "es el sentido propio de actuar" (Heidegger, 1975, p. 393) durante su vida. Así, al Dasein aquello que lo identifica como tal es centralmente poder-ser, que abre y da la posibilidad para llegar a hacer y ser lo que él quiere, le da la posibilidad al ser humano de no ser un autómata, una máquina o algo ya finiquitado, sino poder decidir en cada momento de su vida lo que él puede ser; de ahí que Heidegger establezca que es la posibilidad más libre para el más propio poder ser (Heidegger, 1967, p. 144). En otras palabras, el poder-ser dinamiza la existencia a tal punto que es ahí donde el Dasein sabe lo que pasa consigo mismo.

El Dasein en el poder-ser, dinamiza su existencia porque durante toda su vida está siendo algo, y porque tiene el carácter de proyecto. El proyecto conduce al poder-ser, por ejemplo: a medida que el Dasein toma decisiones, ya en efecto se ha encaminado su poder-ser. La naturaleza del comprender reside en poder-ser. La forma de proyectarse del ser humano abre de determinada manera el mundo, él encuentra las cosas y les da una importancia distinta de acuerdo con su estado de apertura que esté contemplando en el instante. De modo que el Dasein puede estar ante muchas cosas a la mano, pero solo en la medida en que se proyecta su ser es que se vuelven útiles, son significativas y re-cobran su estatus para ser develadas, sin embargo, no solo se descubren tales cosas a la mano, sino que por su proyectar el mismo Dasein se descubre a sí, se conoce en cierta forma y por eso sabe qué es lo que pasa consigo mismo, cómo se siente. Ha de recordarse que el proyecto desde el punto de vista ontológico no es una planificación de su ser (Heidegger, 1967, p. 145), no hay consecuencias de lo que cada uno de nosotros ha elegido ser sino nuevas posibilidades de ser.

El comprender en cuanto poder-ser ha pasado por los existenciales de la posibilidad y el proyecto. Posibilidades y proyecto configuran el poder-ser, son los existenciales fundamentales porque el Dasein mientras existe proyecta sus posibilidades en cada momento de su facticidad. Así que el poder-ser es la constante del ser humano para ser y seguir siendo (ser-siendo-en-el-mundo). Por eso el Dasein no tiene una 
facultad o cualidad de poder hacer algo, sino que es su naturaleza y siempre lo es por la posibilidad abierta de su proyectar, siempre va a poder-algo, o mejor aún, poder-ser-algo.

La posibilidad es el camino que conduce al Dasein para que pueda ser, él puede tener en cada instante de su vida posibilidades y que se presentan como las diversas maneras en que él puede-ser-se al elegir alguna de ellas. Es de señalar que dichas posibilidades están determinadas por el sustrato afectivo, al igual que su inclinación por algunas de ellas; cada posibilidad y elección es elaborada y abierta para su conveniencia y convivencia. El Dasein mientras existe comprende su mundo por disposiciones afectivas, estas determinan de sobremanera la forma como se abre al mundo, como se ex-pone ante las cosas y como las interpreta. Si una situación nos embarga, es porque de cierta forma hemos abierto el mundo en determinadas posibilidades, así que al ser humano de acuerdo con la situación que vive, "le van en su ser varias posibilidades: posibilidades ónticas, afectivas y espirituales” (Cepeda, 2007, p. 63), posibilidades que imprimen, antes que nada, el carácter del ser del Dasein.

El carácter afectivo del Dasein abre y configura su poder-ser, pues ha venido a dar en determinadas posibilidades. Que el Dasein en tanto que está entregado al mundo se abre ante diversas posibilidades en las que puede ser-se y su horizonte en cuanto posibilidad le brinda un esclarecimiento de su ser, al saber qué es lo que le pasa, con razón Heidegger subraya en el parágrafo 31 que "Verstehen ist das existenziale Sein des eigenen Seinkönnens desDaseins selbst, so zwar, daß dieses Sein an ihm selbst das Woran des mit ihm selbst Seins erschließt"17 (1967, p. 144), el comprender es existencial precisamente por aquello que puede ser el ser humano, pero aquí el saber "qué pasa con él mismo" no indica que haga un ejercicio de autoreflexión, sino que afronta su existencia afectivamente, sabe cómo le viene y se siente.

El comprender es el momento como el Dasein vive su mundo, como actúa (Heidegger, 1975, p. 393). El comprender es un modo existencial del ser humano, todo lo que acaece en la cotidianidad se comprende siempre e implícitamente desde un estado de ánimo, de ahí que Heidegger sentencie que el comprender es afectivamente templado, a medida que el Dasein existe es fundamentalmente poder-ser que siempre

17 El comprender es el ser existencial del propio poder-ser del Dasein mismo, de tal manera que este ser abre en sí mismo lo que pasa consigo mismo. 
se proyecta desde sus posibilidades abiertas, es decir como comprender. Con esto se observa que el comprender es lo que puede-ser el ser humano estando en el mundo.

En líneas anteriores se ha explicitado de cierta manera lo que indica tanto el comprender como el poder-ser. Ahora, Heidegger hace patente que el comprender es el ser existencial del poder-ser, queriendo decir que gracias al comprender el Dasein puede ser, sin importar qué, sin caer en atribuciones morales de lo bueno o malo, simplemente lo propio del Dasein es poder-ser mientras es siendo. Lo valioso de esto resulta en que el Dasein se juega su existencia en cuanto se hace, lo que está en juego es su propio ser, de ahí que se haga alusión a que la existencia preceda a la esencia porque el ser humano se hace, porque el Dasein proyecta sus posibilidades y se encuentra simplemente como poder-ser, por eso él existe, comprende su mundo afectivamente abriéndose a su entorno, en sí mismo y viendo lo que pasa consigo mismo.

Las situaciones que experimenta el Dasein en su vida permiten que obtenga cierto conocimiento, no solo de las cosas que lo rodean sino de sí mismo, dependiendo algunas veces de su voluntad y además del estado anímico; a partir de estas estructuras "sabe" comportarse ante la mayoría de las situaciones. Se dice la mayoría, pues el Dasein no sabe cómo se pueda reaccionar ante determinados eventos: algunos quizás son sorpresivos, otros pueden ser tomados como los más superfluos, otros como los más chocantes, pero que están constituidos por la forma como afectivamente comprende su mundo, y en esa constitución afectiva los diversos eventos que pueden ser "normalmente" como los más superfluos pueden tornarse de un momento a otro en los más chocantes y viceversa. En efecto, en cada suceso el ser humano se juega su vida justamente porque puede ser-se, dependiendo de unas condiciones comprensoras y afectivas. De tal suerte, el comprender implica que las personas se caractericen por su forma de ser en medio de su facticidad, porque poseen siempre ya una cierta comprensión no solo de sí mismos con una particular historia personal, sino con los demás, con el mundo y con un cierto horizonte futuro de posibilidades; desde esta perspectiva heideggereana diría Wagner (1938) que "nosotros comprendemos siempre: nos pasamos la vida comprendiendo la propia y la ajena” (p. 64). El Dasein pone en juego su obrar fáctico y comprende en cada caso su situación y la de sus acciones, a partir de las posibilidades abiertas en un determinado proyecto del propio ser personal. Así, el Dasein pasa su cuenta de cobro a la existencia cuando proyecta sus posibilidades y las asume. 
Este segundo lineamiento giró sobre el comprender y el modo como está conformado por los existenciales de la posibilidad, el proyecto y que reposa en el poder-ser, que al fin de cuentas es lo que lo distingue de los otros entes. El Dasein afronta su existencia porque comprende afectivamente desde su condición de arrojado, su facticidad y a su vez proyecta sus posibilidades para que pueda ser.

\subsection{El comprender como interpretación}

Otro de los lineamientos centrales de esta propuesta existencial se encuentra en el parágrafo 32 de Ser y tiempo, aquello que Heidegger denomina como ex-posición o interpretación; allí se manifiesta que "Das Entwerfen des Verstehens hat die eigene Möglichkeit, sich auszubilden. Die Ausbildung des Verstehens nennen wir Auslegung (...). Auslegung gründet existenzial im Verstehen"18 (1967, p. 148). Proyectar quiere decir abrir y en este caso específico abrir un mundo de posibilidades a su existencia; a eso se le ha llamado exposición, por lo tanto, la ex-posición es un modo de apertura que posibilita el poder-ser y las formas de interactuar del ser del ser humano estando en el mundo. En efecto, la ex-posición o interpretación no tiene nada que ver con un ejercicio de la razón, y mucho menos con la explicación de un texto para encontrar su sentido, ¡nada de eso! Como Heidegger muestra cuáles son los procesos que hay dentro del comprender, por eso afirma que la ex-posición se funda en este. También el modo de la posibilidad del proyecto y del poder-ser se fundan en el comprender y su producto final radica en poder-ser, esta es la elaboración o manifestación del comprender: poder-ser.

La exposición tampoco consiste en tomar conocimiento de lo comprendido, sino en elaborar posibilidades, así pues, se confirma que el punto inicial del comprender es la exposición. Exposición significa hacer ver, explicar, explicitar, mostrar y hasta originar en este caso posibilidades, y esto es lo que pasa en cada momento de la vida cotidiana del ser humano. Cuando una persona se mueve en un ámbito constante como puede ser su casa y dentro de ella hay muchísimas cosas (televisor, nevera, comida, mesas, ropa, etc.), en ese instante eso es lo que lo rodea, pero se acuerda o se

18 El proyectarse del comprender tiene su propia posibilidad de desarrollo. A este desarrollo del comprender lo llamamos exposición (...). La exposición se funda existencialmente en el comprender. Auslegung literalmente significa interpretación, aunque su segundo significado es exposición. Sin embargo, para ampliar lo que desea decir Heidegger y evitar malentendidos por las previas maneras de se ha dejado el término exposición como lo sugiere el profesor Rivera en las anotaciones realizadas en Ser y tiempo. 
topa con ellas en la medida en que las necesite y accede a ellas porque le van a servir para algo, así la cosa pensada se hace encontrar, se hace visible, está a la mano y va a cumplir una determinada función, es a esto lo que se le denomina la estructura de algo en cuanto algo, y que es el resultado constitutivo de la interpretación-ex-posición, o mejor, hay una mediación entre ex-posición y comprensión, es una interpretacióncomprensora. Hay un trato entre lo que me rodea (también llamado circunspección) y la ex-posición; a veces las cosas no necesitan decir su función (su para qué), pues sobran las palabras, por ejemplo: una puerta, una mesa, un carro, etc., por eso el hecho de que se haga explícito en lo que lo rodea no quiere decir que de la falta de palabras falte interpretación. No, de ninguna manera. Lo que pasa es que antes de todo enunciado ya se ha comprendido la cosa, esa estructura de "algo en cuanto algo" es previa a todo enunciado, y no por ello se está menospreciando ni rebajando la forma de la ex-posición y del comprender. Puede que se dé la posibilidad de que algo que se tiene a la mano, a la vista, no darle su función para lo que generalmente fue realizada, sino que se queda a la manera de contemplación de las cosas, entonces se dirá que ya no tiene la estructura de algo en cuanto algo y es una privación del ver comprensor.

Con este modo de la ex-posición se podría llegar a pensar entonces que si se tiene algo a la mano, ante los ojos, quiere decir primero que tengo algo ahí y luego le doy su significado, ya sea en cuanto casa, mesa, carro; sin embargo, y según Heidegger, eso es no entender adecuadamente la función de la ex-posición, su función consiste en que aquello que se presenta en medio de todo lo que lo rodea se ha abierto siempre respecto al ser del ser humano. En otras palabras, lo presentado al Dasein es presentado porque se ha abierto en medio de todo lo que lo rodea y se vuelve significativo. La ex-posición como existencial crea, determina, abre las posibilidades de ser del Dasein.

Estos rasgos de la interpretación como la elaboración de posibilidades afincan más la propuesta de una hermenéutica existencial y se arraiga mucho más en la segunda parte de este lineamiento, al afirmar que la interpretación se funda existencialmente en el comprender. En este caso, la interpretación no quiere decir que sea más importante que el comprender, de ningún modo, ella simplemente hace parte del comprender, pero ¿por qué se vuelve tan vital este lineamiento? Porque antes de cualquier acto que se realice ya se han proyectado algunas posibilidades, es decir, ya hay un estado de apertura previo. Sin embargo, el hecho de que se contemplen diversas posibilidades no significa que el Dasein las pueda ver todas, por eso cuando se dice que algo "nos ha tomado por sorpresa" es porque la reacción de tal acto no estaba dentro de las 
posibilidades previstas. La interpretación es una pre-visión y conmemoración, porque tiene la característica de mirar tanto hacia atrás (pasado) como hacia adelante (futuro), ya se ha expuesto y asume lo que le llega en cuanto posibilidad de ser, por eso hace parte esencial del comprender, pues en este se posibilitan los modos como el Dasein ha sido, es y puede ser: la interpretación funda la posibilidad. Ahora bien, el Dasein en cuanto exposición siempre se encuentra abierto para crear y tomar cualquier posibilidad y reaccionar de la manera que sea. La interpretación es -en cierta medida y consecuencia de la existencia- una toma de decisiones (que encaja simultáneamente con los existenciales del proyecto y poder-ser), puesto que el Dasein está siempre viviendo con esa dinámica en su cotidianidad, él decide qué hacer con su facticidad, con su ser existencial. Por eso la interpretación se funda en la comprensión al asumir su existencia, sin lugar a duda.

Por las razones anteriores, la interpretación es uno de los lineamientos fundamentales para la propuesta de hermenéutica existencial; su certificación radica en que la interpretación no es simplemente interpretación textual, sino que al fundirse existencialmente en el comprender la interpretación se hace ante todo fáctica y, en efecto, esto rompe eminentemente con la tradición hermenéutica, pues siempre se ha atribuido que a ella le corresponde solo lo textual. Más aún, en cuanto ex-posición implica que no solo es una toma de decisiones, ni una interpretación de textos, sino que abre la existencia del Dasein radicalmente. Ex-posición indica la apertura (el Ahí), cómo el Dasein se encuentra desplegado en su ser, lo que puede hacer con su ser. Pero si la ex-posición es apertura indica por supuesto que algo se pone al descubierto y esto es producto de la luz, es decir, que la exposición se funda también en el claro de luz.

El Dasein se ex-pone ante su facticidad, se ex-pone de antemano al co-estar con los otros y con las cosas; así esos otros o esas cosas no estén presentes físicamente, el Dasein está en su realidad abierto esencialmente con los otros y naturalmente se afecta. Al ex-ponerse afecta y se afecta, ahora "el afectarse lo uno a lo otro, resulta ser de naturaleza universal, lo que en el ser humano cobra un interés particular que damos en llamar afectividad (...) la afectación es afectiva" (Cepeda, 2007, p. 27). Es afectiva porque el único ente capaz de admirarse, de sentir, de experimentar cosas, de preguntarse por ellas es el Dasein, es un ente que coexiste y co-está con lo(s) demás; donde todas las cosas que existen, que se tienen hoy en día, es gracias a los demás, ya sea desde la ciencia, la tecnología, la cultura, la música, los amigos, nuestros padres y 
todos nuestros seres queridos, todas estas determinaciones prácticamente son nuestro hogar, somos por ellas, nuestra determinación se sitúa entonces en que somos seres incorporados de afectividad por el mundo en que estamos siendo. Por eso Heidegger afirma que uno de los constitutivos originarios del Dasein es la disposición afectiva. Todo lo que rodea al ser humano se halla en el campo de la afectividad, todo lo que interpreta y comprende es afectación afectiva. De ahí que, hasta este momento, al hablar del interpretar, del comprender, sean referentes de una hermenéutica existencial, pues la hermenéutica tal como la analiza Heidegger pone en jaque el modo como ha sido entendida tradicionalmente, de acuerdo con Wagner:

Todo existir es hermenéutico: lo es porque descubre. Al descubrirse lo hace preontológicamente u ontológicamente. Ambas maneras son el mismo fenómeno en grados distintos y por lo tanto propios del existir. La autointerpretación y el análisis existencial se fundan en el existir humano. (1938, p. 68)

Desde la perspectiva heideggereana se sabe que el análisis del existir parte de que "Die Auslegung von Etwas als Etwas wird wesenhaft durch Vorhabe, Vorsicht und Vorgriff fundiert. Auslegung ist nie ein voraussetzungsloses Erfassen eines Vorgegebenen" ${ }^{19}$ (1967, p. 150); al estar estructurada la interpretación por los tres caracteres en la manera del haber previo, del ver previo y del entender previo, permiten que el Dasein en medio de su obrar fáctico pueda descubrir, mostrar y abrir, ocultar y cerrar modos de ser (más que cerrarlos es otro modo de abrirse al mundo) que son originados y determinados en sus posibilidades, porque es un ser que está arrojado al mundo. La interpretación en cuanto exposición puede visualizar, mostrar de antemano un determinado modo de ser a partir de la creación de sus posibilidades, todo fundado gracias a la disposición afectiva y el comprender, pues el interpretar se anticipa o adelanta a un modo de ver y entender pre-vio para ser-se y suscita al Da-sein a mirar su ser y sus posibilidades en cuanto que él es proyectante. De esta manera, se confirma una vez más que la hermenéutica en Ser y tiempo va más allá del arte de la interpretación textual.

Llama la atención cómo Heidegger le da relevancia a la palabra 'previa': en este lineamiento es clave para captar la dimensión en la que se constituye cualquier tipo

19 La interpretación de algo en cuanto está esencialmente fundada en el haber previo, en la manera previa de ver y en la manera de entender previa. La interpretación no es jamás una aprehensión, sin supuestos, de algo dado. 
de interpretación, ya sea fáctica o textual, por eso se afirma que como ya hay algo dado de antemano, el ser humano se encuentra arrojado y más aún predeterminado a ciertas condiciones. Heidegger enseña esta estructura de la interpretación ilustrando lo que sucede cuando una persona lee un texto: por una parte está el texto, ya hay algo que es el texto (haber previo), en segundo lugar ya hay unos prejuicios que puede suscitar afecciones como de curiosidad, inquietud, duda, de intuición u otro tipo que conllevan al modo como proyecta su lectura y entiende las cosas (ver previo), en tercer lugar, una vez leído el texto se extraen las propias deducciones para validar lo que previamente se le había dado (entender previo).

También se deriva el tema de la pre-comprensión que se declara en el parágrafo segundo cuando Heidegger lanza su sentencia de que todo preguntar es un buscar y "está guiado previamente por aquello que se busca" (1967, p. 28) puesto que al preguntar por algo se puede (quizás sí o quizás no) tener ciertos indicios o nociones para acertar en su respuesta. Si la pregunta se hace explícita, es decir, no solo es hablar por hablar ${ }^{20}$, sino que si la pregunta se refiere al campo estrictamente teoréticoepistemológico, se encuentra entonces fundado en el campo de la investigación, esta ofrece sus resultados teoréticos y así se origina el concepto de ese algo por el que se pregunta. En este caso la investigación de Ser y tiempo tiene indicios de la historia de la filosofía y pregunta por el ser y su sentido. Ahora bien, la cuestión de preguntar por el ser se radicaliza particularmente en el Dasein que es capaz de develarlo bajo tres componentes interpretativos: el haber, el ver y entender previos. Así, en la exposición o interpretación se puede vislumbrar que en el haber, ver y entender previos es como el Dasein capta el mundo, por eso busca siempre conocer las cosas y por consiguiente vivir su cotidianidad, en medio de un ir y venir de disposiciones afectivas.

\subsection{El sentido}

El último de los lineamientos radica en el existencial que Heidegger denomina sentido; él afirmará que cuando un ente es descubierto por el Dasein y cuando es comprendido se dice que tiene sentido, pero lo descubierto no es el sentido como tal sino el

20 El término que usa Heidegger para esta expresión es: 'hablilla' como se puede ver en Ontología hermenéutica de la facticidad. Hablar por hablar significa la mera charlatanería o el simple hecho de chismosear por alguien o por las cosas. Es el mismo término que se utiliza en el parágrafo 36 en Ser y tiempo, como se observó en el capitulo anterior. 
ser del ente. Ahora bien, la función que brinda el sentido es la de ser articulación entre la aperturidad y la interpretación comprensora. Según esto, se podría afirmar que el concepto de sentido es importante porque ayuda a comprender de mejor manera el ser del ente, pero hay que tener cuidado en afirmar que sentido y ser sean lo mismo. El sentido es el camino más directo para captar la comprensión de ser; es justamente la articulación, el enlace, lo que recubre, el mecanismo para facilitar el punto de encuentro con algo y por este motivo Heidegger subraya principalmente que el "Sinn ist das durch Vorhabe, Vorsicht und Vorgriff strukturierte Woraufhin des Entwurfs, aus dem her etwas als etwas verständlich wird (...) Nur Dasein kann daher sinnvoll oder sinnlos sein"21 (1967, p. 151), si el sentido es el horizonte indica entonces que es el telón de fondo sobre el cual se inicia la comprensión y a su vez es su punto máximo, se comprende porque hay sentido. Lo que no es interpelado por la comprensión tan solo no tiene sentido para el Dasein.

El horizonte es el panorama, es el espacio concreto donde se juegan las posibilidades del ser del Dasein, en cuanto que todo ente que está ahí puede ser descubrible y lo asimila a la manera como ha descubierto otras cosas previamente, por eso todo lo que deviene, todo lo que acaece en la forma como el Dasein se proyecta es interpretado de antemano por las concepciones, prejuicios y formas que habitan en el Dasein; estas son las concepciones previas del haber, el ver previo, y entender previo; sin embargo, semejantes prejuicios o bien son descartados o confirmados a la hora de interactuar lo que se está descubriendo. De ahí que el horizonte sea el medio donde se conocen las cosas, pero la relevancia del sentido cobra importancia para Heidegger cuando declara que solo el ente que pregunta por el ser puede estar dotado de sentido. Que esté dotado de sentido indica la cualidad, la capacidad y la naturaleza que identifica al Dasein de un ente cualquiera, pero en dado caso, si un Dasein no llegara a tener sentido desde la perspectiva heideggereana se deduce o bien que no comprendería, que no existe o que ha muerto.

El sentido es el medio por el cual el ser humano comprende las cosas, de cómo las asume cuando interactúa con ellas. No obstante, este concepto de sentido en Heidegger parece encontrarse limitado, pues aunque lo declare como existencial

21 Sentido es el horizonte del proyecto estructurado por el haber previo, la manera previa de ver y la manera de entender previa, horizonte desde el cual algo se hace comprensible en cuanto algo (...). Por eso solo el Dasein puede estar dotado de sentido o desprovisto de él. 
siempre está dirigido a un medio de conocer las cosas (véase cuando habla del círculo del comprender cuando pone el ejemplo del modo del conocer de la ciencia), conocer que por supuesto está arraigado a la existencia del ser humano en medio de las cosas, de la cotidianidad y este es un paso fundamental del giro hermenéutico que da Heidegger respecto de lo tradicionalmente entendido, pero que no es el sentido al que se intenta llevar a cabo en esta propuesta existencial) o por lo menos, Heidegger no explicita exactamente cómo el sentido afecta la existencia en su cotidianidad, se le reconoce exponer su estructura general y lo previamente dado como configuración de sentido y también al proponer cómo los fenómenos de la ambigüedad, la curiosidad y el hablilla intervienen y llevan a cabo el modo de vida de la mayoría de las personas. Quiérase o no, el sentido al que se está refiriendo es al cómo se conocen las cosas y que son compartidas entre unas y otras personas, pero que no alcanza a ahondar y explorar las sendas del sentido de la misma existencia del ser humano, por eso como estos parágrafos son la raíz hermenéutica, paradójicamente, en ellos está su vacío. Es cierto que la segunda parte del capítulo quinto se preocupa por la cotidianidad del Ahí del Dasein que lo determine como lo propio y lo impropio, pero no lo refleja de manera suficiente para la propuesta existencial, aunque sí muestra su estructura. El sentido en Heidegger corresponde entonces a las estructuras generales de la constitución del Dasein, es lo que ontológicamente lo diferencia de otros entes, estos pueden ser un sinsentido e incluso un contrasentido para el Dasein, como bien lo ilustra Ser y tiempo en el parágrafo 32: puede llegar el punto de ir no solo en contra del ser del Dasein sino de acabar con su vida.

Las anteriores afirmaciones parecen estar invertidas o ser contradictorias si se tiene en cuenta que el mismo Heidegger declara que al preguntarse por el ser y su sentido no necesariamente la investigación se vuelve más profunda si antes no se pregunta por el ser desde lo que comprende el Dasein, "Der Sinn von Sein kann nie in Gegensatz gebracht werden zum Seienden oder zum Sein als tragenden »Grund « des Seienden, weil »Grund « nur als Sinn zugänglich wird, und sei er selbst der Abgrund der Sinnlosigkeit"22 (1967, p. 152). Esta es la clave para comprender la situación fáctica del mismo ser humano, como se entrevé, Heidegger la anuncia, pero parece

22 "El sentido del ser no puede ser jamás contrapuesto al ente o al ser en cuanto "fundamento" sustentador del ente, puesto que el "fundamento" solo es accesible como sentido, aunque solo fuere como el abismo del sinsentido". 
que se le olvida desarrollarla y eso será al mismo tiempo lo que ha de esclarecer una hermenéutica existencial.

Por estas razones, un posterior despliegue de la hermenéutica existencial ha de intentar llenar estos vacíos. El propósito de este trabajo ha cumplido con vislumbrar una hermenéutica existencial en Ser y tiempo que es la base de esta propuesta, pero donde aún queda mucho por hacer; sería necesario para su desarrollo determinar por ejemplo qué formas o categorías específicas afectivas del ser humano se pueden vislumbrar y prever el horizonte ontológico de esta propuesta.

\section{La hermenéutica existencial ${ }^{23}$}

Al hablar sobre hermenéutica existencial en Ser y tiempo es preciso observar lo que Heidegger entiende por hermenéutica. En el parágrafo séptimo de esta obra Heidegger muestra sintéticamente tres sentidos sobre hermenéutica, él está hablando de que realizar una ontología fundamental ha de tener como hilo conductor al ente que goza de la primacía óntico-ontológica: el Dasein, que es el único capaz de hacer la pregunta por el ser y su sentido (1967, p. 37). Así, el primer sentido de hermenéutica que Heidegger considera tiene el carácter de $\varepsilon \rho \mu \varepsilon v \varepsilon v ́ \varepsilon \imath v$, es decir, el quehacer de la interpretación, que consiste en hacer un estudio del Dasein (el ente que en cada caso somos nosotros mismos) para que desde la interpretación se descubran y anuncien las estructuras más importantes de este ente, y así lograr una mejor comprensión del ser ${ }^{24}$. El segundo sentido de la hermenéutica radica en que una vez realizada la interpretación sobre el Dasein es posible hacer todo tipo de interpretación sobre cualquier ente, y es hermenéutica porque implica poder elaborar la posibilidad ${ }^{25}$ de todo tipo de investigación en ontología de cualquier ente. El tercer sentido para

23 Este segundo apartado del texto resulta siendo la conclusión a que hemos llegado, tanto como fruto de lo presentado en la primera parte, como al interior del grupo de investigación; por esta razón no habrá una sección diferente a la que se le llame "conclusiones".

24 Se puede remitir al parágrafo tres del curso de Ontología hermenéutica de la facticidad. Alli Heidegger sostiene que la hermenéutica, sosteniendo que en cuanto interpretación ha de ser vista en el modo en que se pueda comunicar algo sobre la facticidad del Dasein.

25 Se observó en el capitulo dos (2.1.1.2) que la interpretación es la elaboración de las condiciones de posibilidad de ser del Dasein. En este caso, elaborar la posibilidad, se refiere a que se abre todo tipo de investigación que el Dasein puede hacer de todo tipo de ente. 
Heidegger es el más importante, porque "die Hermeneutik als Auslegung des Seins des Daseins einen spezifischen dritten den, philosophisch verstanden, primären Sinn einer Analytik der Existenzialität der Existenz"26 (1967, p. 38). Lo que Heidegger intenta hacer es observar al Dasein y analizarlo desde su cotidianidad ${ }^{27}$ donde se perciben elementos esenciales que constituyen su ser. Así, lo que se desarrolla en Ser y tiempo es la analítica de la existencia y por eso afirma Heidegger que la filosofía tiene su punto de partida en la hermenéutica del Dasein, y a su vez, confirma que una ontología fundamental ha de desarrollarse desde el mismo Dasein donde puede develarse el ser mismo, pero por supuesto desde la hermenéutica.

Hablar de una hermenéutica existencial parte de lo que Heidegger ha dado en llamar como hermenéutico-existencial: El "Das ursprüngliche »Als« der umsichtig verstehenden Auslegung ( $\dot{\varepsilon} \rho \mu \eta \varepsilon \dot{\alpha} \alpha)$ nennen wir das existenzial-hermeneutische"28 (1967, p. 158), haciendo referencia con todo lo que tiene que ver con la vida fáctica del Dasein. Es así como hablar de hermenéutica existencial ${ }^{29}$ parte de la interpretación que se pueda hacer del ser humano, no como una teoría del conocimiento sino como ejercicio de comprender de otro modo al ser humano, en su modo más natural, su ser puesto en evidencia en el trajinar de la vida cotidiana. Desde esta perspectiva, el sentido de la hermenéutica en Heidegger sobre el comprender y la interpretación rompe con la conocida tradicional definición de hermenéutica: el arte de la interpretación especialmente de textos, que pretende rescatar y renovar su sentido originario (Gadamer, 2010, p. 98).

Darle calificativo a esta hermenéutica como existencial es porque parte de las estructuras fundamentales que hacen ser al ser humano y todo lo que tiene que ver

26 La hermenéutica cobra, en cuanto interpretación del ser del Dasein, un tercer sentido específico, filosóficamente hablando el primario: el sentido de una analítica de la existencialidad de la existencia.

27 Cuando Heidegger afirma que la existencialidad de la existencia lo conduce, en pocas palabras, a realizar una analítica del Dasein. Sin embargo, también se puede interpretar como hacer es un análisis existencial de la existencia del Dasein. Ahora, si el punto de partida ha de considerarse desde la hermenéutica, como lo afirmaba Heidegger entonces, es en este sentido que se puede desarrollar también una hermenéutica de carácter existencial. Una referencia de este análisis se puede encontrar cuando Heidegger reflexiona en los parágrafos 36 a 38 (véase capitulo dos) donde se refiera al hablilla, la curiosidad y la ambigüedad.

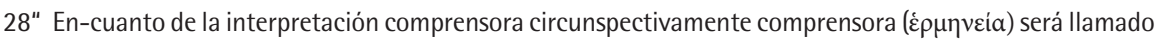
'en cuanto" hermenéutico-existencial".

29 Lo existencial se refiere a todo aquello que tiene que ver con el ser humano, sus estructuras fundamentales y demás. 
con su vida; es existencial porque las estructuras están determinadas y se evidencian desde su existencia y no de un ente cualquiera: "Weil sie sich aus der Existenzialität bestimmen, nennen wir die Seinscharaktere des Daseins Extstenzialien. Sie sind scharf zu trennen von den Seinsbestimmungen des nicht daseinsmäßigen Seienden, die wir Kategorien nennen"30 (Heidegger, 1967, p. 43) así, pues, es claro que el carácter existencial está referido expresamente a todo aquello que tiene que ver con el Dasein, pero bien diferencia Heidegger que una cosa es hablar de las estructuras del Dasein y otra muy distinta hablar de las estructuras de un ente cualquiera, pues esas estructuras se les llamará categoriales, así que un referente de la hermenéutica existencial indica "pensar la existencia misma como realización o consumación de comprensión e interpretación” (Gutiérrez, 2002, p. 103). Entonces se puede entrever que la perspectiva de Heidegger sobre la hermenéutica es muy diferente de la habitual concepción; aquí hay un giro existencial, pues está inclinada sobre el estudio que se realizó sobre el Dasein. ¿Es posible entrever una hermenéutica existencial en Heidegger? Sí, sí es posible, porque parte de conceptos centrales de la hermenéutica como el comprender y la interpretación, la hermenéutica ya no es la forma como alguien "quien no comprendía un texto acudía a una interpretación que servía de medio ocasional para llegar a la comprensión como intelección” (Gutiérrez, 2008, p. 71). El comprender no como el arte de entender ni como el arte de interpretar textos, sino que se juega la existencia del ser humano ya dice demasiado, de ahí que esta hermenéutica se le pueda calificar como existencial ${ }^{31}$, puesto que parte de la situación afectiva en que se encuentra el ser del ser humano, y desde ahí cobra sentido su vida.

En el parágrafo 32 cuando Heidegger sostiene que el sentido es fundamental en la existencia del ser humano, dice:

Und wenn wir nach dem Sinn von Sein fragen, dann wird die Untersuchung nicht tiefsinnig und ergrübelt nichts, was hinter dem Sein steht, sondern fragt nach ihm selbst, sofern es in die Verständlichkeit des Daseins hereinsteht. Der Sinn von Sein kann nie in Gegensatz gebracht werden zum Seienden oder zum

30 Como estos caracteres de ser del Dasein se determinan desde la existencialidad, los llamamos existenciales. Se los debe distinguir rigurosamente de las determinaciones de ser del ente que no tiene la forma de ser del Dasein, a las que damos el nombre de categorias.

31 Aqui radica la intención de este trabajo: develar una hermenéutica existencial y al mismo tiempo elaborar su posible arquitectónica. 
Sein als tragenden »Grund « des Seienden, weil »Grund « nur als Sinn zugänglich wird, und sei er selbst der Abgrund der Sinnlosigkeit ${ }^{32}$. (1967, p. 152)

Heidegger señala que la manera como se tienen noticias por el sentido del ser es a través de lo que vive el ser del ser humano inmerso en el mundo, en la forma como interactúa en su entorno y lo que siente en el ahí y ahora. La forma de investigar la pregunta por el sentido del ser parte originariamente de la vida fáctica y no con presupuestos teóricos solamente, por eso afirma que el sentido del ser no puede ser algo que vaya en contra del Dasein, sino que parte de este ente desde donde emerge su sentido.

Ahora, desde nuestra perspectiva existencial la clave de este pasaje radica cuando el pensador dice 'accesible como sentido', es un eslabón que identifica a esta hermenéutica. La vida del ser humano ha de tener algún sentido e incluso cuando todo parezca estar al borde del abismo, la desazón de la vida. El sentido le permite desde y para el Dasein hallar respuesta a la pregunta por el sentido del ser en general. La hermenéutica no debería reducirse a un ejercicio que tiene que ver con lo cognoscitivo y la interpretación de textos, sino con la vida misma de quien interpreta. Existencial quiere decir que es un fundamento primordial en la vida del ser humano, que todo lo que existe le afecta en su ser. Una hermenéutica existencial abre una puerta de acceso a nuevas formas de entender al ser humano en cuanto que es poseedor de sentido. El sentido ha de orientar el valor hacia la vida, para poder entender por qué algunos estados de ánimo parecen pesar más que otros que en algunas circunstancias son determinantes para que un ser humano pierda su sentido y en efecto pierda su vida. Se puede deducir que, desde la propuesta existencial, el sentido es el germen de la vida, el fundamento y construcción de la misma existencia ${ }^{33}$. En esta hermenéutica se juega la existencia del ser humano y su sentido más propio; una hermenéutica que vaya más allá de los textos y se enraíce en las entrañas del ser humano tendrá

32 Cuando preguntamos por el sentido del ser, la investigación no se torna por eso profunda, ni intenta alcanzar, a costa de cavilaciones, algo que estuviera detrás del ser, sino que pregunta por el ser mismo en tanto que inmerso en la comprensibilidad del Dasein. El sentido del ser no puede ser jamás contrapuesto al ente o al ser en cuanto "fundamento" sustentador del ente, puesto que el 'fundamento' solo es accesible como sentido, aunque solo fuere como el abismo del sinsentido.

33 Lo que está en juego en este trabajo es el tema del sentido, tema por cierto del que nos equiparó Heidegger. Tema del que se intenta brindar una propedéutica de la forma de ser del ser humano, de cómo comprender su afectividad, y donde quizá, llegado a este punto se pueda intentar vislumbrar las crisis por las que atraviesan las sociedades actuales, es decir, de su sentido o sinsentido que puede residir. 
un profundo sentido existencial, y bajo su horizonte también los textos cobrarán un nuevo y renovado sentido. Estamos, pues, a las puertas de una nueva posibilidad de ser.

\section{Referencias}

Cepeda, J. (2007). Ontología de la educación. Lineamientos de filosofía de la educación con sentido de ser. Bogotá: Whity.

Cepeda, J. (2003). La pregunta por el ser en Heidegger. Recuperado de http://www. antroposmoderno.com/antro-articulo.php?id_articulo=356

Cepeda, J. (2017). Sentipensar ontológico. Bogotá: AutoresEditores.

Gutiérrez, C. B. (2002). Temas de filosofía hermenéutica: conferencias y ensayos. Bogotá: Uniandes.

Gutiérrez, C. B. (2008). Ensayos hermenéuticos. México: Siglo XXI.

Heidegger, M. (1961). Nietzsche. Frankfurt am Main: Vittorio Klostermann.

Heidegger, M. (1967). Sein und Zeit. Tubingen: Max Niemeyer Verlag.

Heidegger, M. (1975). Die Grundprobleme der Phänomenologie. Frankfurt am Main: Vittorio Klostermann.

Heidegger, M. (1983). Die grundbegriffe der Metaphysik: Welt - Endlichkeit Einsamkeit. Frankfurt am Main: Vittorio Klostermann.

Heidegger, M. (2000a). Problemas fundamentales de la fenomenología. Madrid: Trotta.

Heidegger, M. (2000b). Nietzsche I. En J. Vermal (Trad.). Barcelona: Destino.

Heidegger, M. (2002). Grundbegriffe der aristotelischen Philosophie. Frankfurt am Main: Vittorio Klostermann.

Heidegger, M. (2006). Ser y tiempo. En J. Rivera (Trad.). Madrid: España Trotta.

Ricouer, P. (2013). La hermenéutica y el método de las ciencias sociales. Cuadernos de Filosofía latinoamericana, 34 (109), 57-70.

Wagner, A. (1938). La ontología fundamental de Heidegger. Buenos Aires: Losada.

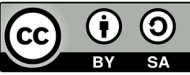


